\title{
D-OPTIMAL RESPONSE MIXTURE DESIGN MODELING OF POLYSTYRENE WASTE ADHESIVE FORMULATIONS
}

\author{
Lucas Albert Jerome Hamidu ${ }^{1}{ }^{\mathbb{}}$, Umar Omeiza Aroke ${ }^{2}$, Odeh Adey Osha ${ }^{3}$, Idris \\ Misau Muhammad 2 \\ ${ }^{1}$ Nigerian Building and Road Research Institute 10, NBRRI Way/ I.T. Igbani Street, off Awolowo \\ Way, Jabi, Abuja, Nigeria \\ 2 Department of Chemical Engineering, Abubakar Tafawa Balewa University, P.M.B. 0248, Bauchi, \\ Nigeria \\ ${ }^{3}$ Department of Chemical Engineering, University of Calabar, P.M.B. 1115, Calabar, Nigeria
}

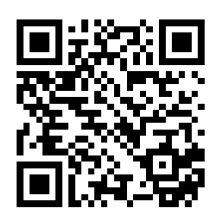

DOI: https://doi.org/10.29121/ijetmr.v8.i3.2021.867

Article Citation: Lucas Albert Jerome Hamidu, Umar Omeiza Aroke, Odeh Adey Osha, and Idris Misau Muhammad. (2021). DOPTIMAL RESPONSE MIXTURE DESIGN MODELING OF POLYSTYRENE WASTE ADHESIVE FORMULATIONS. International Journal of Engineering Technologies and Management Research, 8(3), 717.

https://doi.org/10.29121/ijetmr.v8 .i3.2021.867

Published Date: 12 March 2021

Keywords:

Adhesive

D-Optimal Mixture Design

Formulation

Modeling

Polystyrene Waste

Response

\section{ABSTRACT}

The importance of polystyrene in handling and transportation of fragile equipment for safe delivery cannot be under stated. However; the post-usage has raised serious concern due to adverse effects caused by the litters on environment in blocking water-ways due to its weightlessness, release of oxides of carbon and resisting decomposition among others. This work was intended to model produced adhesive from polystyrene waste using Design Expert version 6.0.8 software and D-optimal mixture design for the responses analyses to obtain the best adhesive. Eight (8) experimental runs were generated for resin formulations with only 3 feasible, coded: R1, R4 and R7, based on 2 factorial design of experiment for resin formulations. Furthermore, 14 adhesive formulations were generated for each resin, coded: R1AD, R4AD and R7AD, that is, the formulated resin was combined with additives to produce adhesive using 3 factorial mixture designs and 4 responses, namely: viscosity, $\mathrm{pH}$, percentage moisture content and percentage solid content. The responses were modeled using D-optimal mixture design: the viscosity response modeling was best fitted with quadratic model for R1AD produced adhesives, while R4AD and R7AD produced adhesives were fitted with Cubic model. The $\mathrm{pH}$, percentage moisture content and percentage solid content responses were all fitted with cubic model based on the statistical and modeled data. The modeling solution was further optimized and validated for the three adhesive productions, the general selection of produced adhesive based on desirability factor and line with experimental analyses from the responses shows: R7AD2 $>$ R4AD1 $>$ R1AD1 produced adhesives in the order of fitness.

\section{INTRODUCTION}

Polystyrene waste disposal has been a subject of intense research due to its non-degradability. It is a synthetic aromatic polymer product produced from the styrene monomer during the alkylation of benzene reaction with ethylene to produce ethyl benzene [18], the styrene monomer which is covalently linked together with many

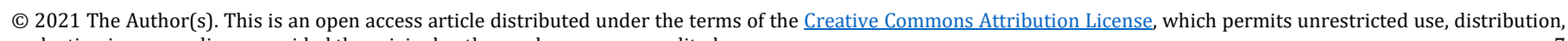
and reproduction in any medium, provided the original author and source are credited. 
monomers form polymer known as polystyrene with chemical formula $\left[-\mathrm{CH}_{2}-\mathrm{CH}-\left(\mathrm{C}_{6} \mathrm{H}_{5}\right)-\right]_{\mathrm{n}}[3]$ and structural formula presented in Figure (1) [38].

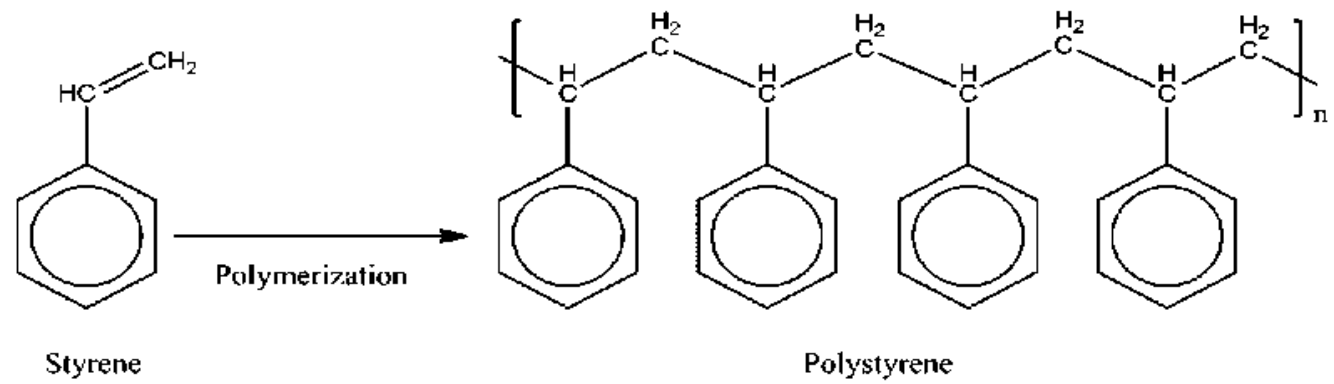

Figure 1: The reaction scheme for the synthesis of polystyrene from monomer - styrene.

The global production of polystyrene is about 14 million tons annually with about $80 \%$ end-up in landfills and the remaining $20 \%$ in water ways [24]. It is the reliable modes of packaging, transportation and protection of sensitive devices, fragile equipment, electrical appliances and others for safe delivery. However, its post usage has been a global challenge as recycling is not economical due to its weightlessness and low cost [33], burying in the soil leads to prevention of water infiltration to ground [10] while burning releases carbon (IV) oxide aiding global warming [15], [29]. Some research works carried out on the recycling or reuse of polystyrene waste includes: formulation of adhesive for particleboard [1], [17] and binder to cushion the effect of formaldehyde emission in paint $[4]$.

The growing concern to maximize wastes generated and conversion to usefulness is the drive for the concept of adhesive from polystyrene waste, which could offer opportunity to utilize in adhesive production for use in composite production such as "particleboard from lignocellulose waste material". Adhesive is a substance that when applied to the surface of an object such that the two or more become bonded together by surface attachment [35], such bonding could be due to Van de Waals forces of chemical attraction [9]. Adhesive formulation is either solvent base or water-borne or $100 \%$ solid hot-melt [37]. In development of new product, scientific approach is mostly adopted to find the best formulation by modeling which is usually analyzed using various statistical tools to determine the fitness. Accordingly, adhesive formulation is by combination of different components such as: tackifyer for resin formulation [26], [39] and additives for stabilization of adhesive [17]. The choice of plasticizer additive depends on the type of polymer compatibility of the oil, availability and cost such as dibenzoate [5] while antioxidant additive prevents oxidization, maintain stability and resist thermal degradation of adhesive when exposed to ultra-violet [8], it also hinders change in adhesive viscosity and char formation using typical antioxidant such as hindered amines [5], [36].

Modeling is a process of formulation using mathematical equations, showing the behavior that characterized the process by the response surface method [21], it is the essentials that can be experimentally verified in order to solve the problem or improve on the existing process condition [31], leading to establishment of the relationship between the response concern and the input. The variables are used to predict the responses that can be compared with experimental values [25] using mathematical model equation as presented in Eq. (1) [35].

$$
Y=\beta_{0}+\beta_{1} A+\beta_{2} B+\beta_{3} C
$$

Where $Y=$ Predicted response, $\beta_{0}=$ Intercept while $\beta_{1}, \beta_{2}$ and $\beta_{3}$ are the model coefficient for the factors $A, B$ and $\mathrm{C}$ respectively.

Experimental design approach is extensively employed to optimize several processes in modeling to achieve a desired result, this includes: modeling in extraction of volatile compounds in turmeric leaves [40], response surface methodology as tool for heavy clay firing optimization process [7], optimization of alkaline protease production from Bacillus sp. using modeling [11] and D-optimal for optimization of extraction yield, viscosity and oil analysis [20]. Furthermore, design of experiment (DOE) approach was applied to understudy the behavior in formulation of adhesive with acceptable plasticizer based on the design and response variables [6], the effects of test variables in shear strength of adhesive produced and followed by analysis of data using one-way analysis of variance (ANOVA) to compare with regression [12], and D-Optimal mixture design in optimization of ternary matrix blends for 
controlled zero-order drug release from oral dosage [14]. Thermal mixture DOEs as an alternative method in optimizing the aqueous phase composition of a microemulsion was carried out [19], D-Optimal mixture design to compare with other experimental design to study logistic for regression analyses [22] and regression model to predict the California bearing ratio (CBR) values of black cotton soil for stabilization of cement [2].

Statistical and data analysis by different models such as: linear model, 2FI model, quadratic model, cubic model [32], [41] and special cubic model [30] are usually generated by the Design Expert software for determination of the best model. Each model analyzes the response interaction between the manipulated variables and non-manipulated variables using the statistical tools. Amongst these model techniques, D-optimal which is a design for categorical factors minimizes errors associated with model coefficient that could provide an efficient means to optimize processes depending on the choice of factors for the formulation to provide desirable response. Furthermore, other factors considered in suggesting the validity of the achieved results by using ANOVA which describe the fitness of the model curves are the predicted and adjusted coefficient of correlation $\left(\mathrm{R}^{2}\right)$ values which should be in agreement of not more than 0.2 difference with precision accuracy greater than 4; whereas if precision accuracy less than 4 , it implies that such model is not significant [16], [30]. F-values which compare the average experimental errors associated with P-values are used in confirming the model significance or insignificance for individual terms tested [16]. If the predicted value of a model is negative, the mean model is suggested for RSM or linear model for mixture, the lack of fit appears when replication occurs in model with a desirable P-value greater than 0.1 which implies insignificant model. However, significant models have real effect on the responses if $P>F$ values is less than 0.05 , while greater implies insignificant model [23]. In this work, the produced adhesives from polystyrene waste [17] was modeled to determine the best fits among several formulations based on the mixture design matrices and Doptimal mixture design responses.

\section{MATERIALS AND METHODS}

The experimental procedure for material collection, pretreatment, washing and fragmentation method adopted was reported in a separate publication [17]. Design expert 6.0.8 version software was employed for the experimental design with the design variables: polystyrene waste in the range of $0.5 \leq \mathrm{PS} \leq 0.75$ and tackifyer in the range of $0.25 \leq \mathrm{TKF} \leq 0.50$ for resin formulation based on 2 factorial designs as presented in Table 1 and Eq. (2) for the component of resin formulation.

Table 1: Experimental Mixture Design for Resin Formulations

\begin{tabular}{|l|l|l|l|}
\hline & \multicolumn{3}{|c|}{ Components (g) } \\
\hline Resin & PS & Tkf & \\
\hline R1 & 0.5000 & 0.5000 & \\
\hline R2 & 0.5000 & 0.5000 & \\
\hline R3 & 0.6875 & 0.3125 & \\
\hline R4 & 0.6250 & 0.3750 & \\
\hline R5 & 0.7500 & 0.2500 & \\
\hline R6 & 0.5000 & 0.5000 & \\
\hline R7 & 0.5625 & 0.4375 & \\
\hline R8 & 0.5000 & 0.5000 & \\
\hline
\end{tabular}

$$
\mathrm{R}=\mathrm{PS}+\mathrm{TKF}
$$

Where $\mathrm{R}=$ resin, $\mathrm{PS}=$ Polystyrene waste and TKF $=$ Tackifyer.

The design expert generated eight (8) experimental runs for resin formulations (R) with duplication (R1, R2, $\mathrm{R} 6, \mathrm{R} 8)$ and had runs $(\mathrm{R} 3, \mathrm{R} 5)$ not forming resin due to inadequacy of the ratios to dissolve the polystyrene, thereby resulting into three feasible resin formulations R1, R4 and R7. The feasible resin formulations produced was further designed for adhesive formulation with added additives namely: plasticizer and antioxidant being the variables for 3 factorial designs with 4 responses (viscosity, $\mu$; proton of hydrogen, $\mathrm{pH}$; percentage moisture content, \%MC and percentage solid content, \%SC). Plasticizer was synthesized from benzoic acid and diethylene glycol to form diethylene glycol dibenzoate [6]. The antioxidant (diphenyl amine) was ground to powdered and sieved with $400 \mu$ 
- $1.8 \mathrm{~mm}$ aperture mesh without further modification. The design expert generated fourteen (14) experimental runs (Tables 2, 3 and 4) with the design variable ranges: resin $0.65 \leq \mathrm{R} \leq 0.79$, plasticizer $0.20 \leq \mathrm{PLZ} \leq 0.34$ and antioxidant $0.009 \leq \mathrm{AOX} \leq 0.01$ and the component adhesive formulations (Eq. (3)).

$$
\mathrm{AD}=(\mathrm{R}+\mathrm{PLZ}+\mathrm{AOX})
$$

Where $\mathrm{AD}=$ adhesive, $\mathrm{R}=$ Resin, $\mathrm{PLZ}=$ plasticizer and $\mathrm{AOX}=$ antioxidant.

\section{RESULTS AND DISCUSSION}

The experimental result for the produced adhesives and the corresponding characterized responses is presented Tables 2-4 for the feasible resins formulated from R1, R4 and R7 respectively.

Table 2: Determined Responses of Resin R1 Produced Adhesives

\begin{tabular}{|c|c|c|c|c|c|c|c|}
\hline Adhesive & R1 & PLZ & AOX & $\mu(\mathrm{cPc})$ & $\mathrm{pH}$ & $\% \mathrm{MC}$ & $\% \mathrm{SC}$ \\
\hline AD1 & 0.76 & 0.23 & 0.01 & 2431 & 3.10 & 7.57 & 68.16 \\
\hline AD2 & 0.79 & 0.20 & 0.01 & 1925 & 3.60 & 11.00 & 68.22 \\
\hline AD3 & 0.72 & 0.27 & 0.01 & ND & 5.90 & 11.45 & 71.69 \\
\hline AD4 & 0.65 & 0.34 & 0.01 & ND & 6.10 & 11.54 & 62.15 \\
\hline AD5 & 0.65 & 0.34 & 0.01 & ND & 6.09 & 11.56 & 62.17 \\
\hline AD6 & 0.79 & 0.20 & 0.01 & 1923 & 3.40 & 11.18 & 68.20 \\
\hline AD7 & 0.79 & 0.20 & 0.01 & 1926 & 3.60 & 11.20 & 70.45 \\
\hline AD8 & 0.79 & 0.20 & 0.01 & 1925 & 3.55 & 12.33 & 69.55 \\
\hline AD9 & 0.79 & 0.20 & 0.01 & 1925 & 3.70 & 12.31 & 68.31 \\
\hline AD10 & 0.76 & 0.23 & 0.01 & 2430 & 3.20 & 7.63 & 68.10 \\
\hline AD11 & 0.65 & 0.34 & 0.01 & ND & 6.05 & 11.60 & 72.15 \\
\hline AD12 & 0.65 & 0.34 & 0.01 & ND & 6.00 & 11.58 & 72.53 \\
\hline AD13 & 0.65 & 0.34 & 0.01 & ND & 6.10 & 11.54 & 71.63 \\
\hline AD14 & 0.69 & 0.30 & 0.01 & 1577 & 6.30 & 17.85 & 55.51 \\
\hline
\end{tabular}

*ND=Not detected by viscometer probably due to lack of fit

Table 3: Determined Responses of Resin R4 Produced Adhesives

\begin{tabular}{|c|c|c|c|c|c|c|c|}
\hline Adhesive & R4 & PLZ & AOX & $\mu$ (cPc) & $\mathrm{pH}$ & $\% \mathrm{MC}$ & $\% \mathrm{SC}$ \\
\hline AD1 & 0.76 & 0.23 & 0.01 & 5240 & 4.60 & 13.57 & 65.41 \\
\hline AD2 & 0.79 & 0.20 & 0.01 & 5259 & 5.40 & 10.74 & 65.15 \\
\hline AD3 & 0.72 & 0.27 & 0.01 & 5250 & 5.40 & 11.54 & 69.84 \\
\hline AD4 & 0.65 & 0.34 & 0.01 & 4846 & 5.60 & 8.76 & 75.50 \\
\hline AD5 & 0.65 & 0.34 & 0.01 & 4845 & 5.62 & 8.80 & 74.98 \\
\hline AD6 & 0.79 & 0.20 & 0.01 & 5200 & 5.43 & 10.94 & 65.10 \\
\hline AD7 & 0.79 & 0.20 & 0.01 & 5199 & 5.43 & 10.96 & 65.11 \\
\hline AD8 & 0.79 & 0.20 & 0.01 & 5199 & 5.41 & 11.01 & 65.19 \\
\hline AD9 & 0.79 & 0.20 & 0.01 & 5200 & 5.42 & 10.72 & 65.14 \\
\hline AD10 & 0.76 & 0.23 & 0.01 & 5241 & 4.64 & 13.55 & 65.45 \\
\hline AD11 & 0.65 & 0.34 & 0.01 & 4847 & 5.61 & 8.82 & 75.30 \\
\hline AD12 & 0.65 & 0.34 & 0.01 & 4848 & 5.59 & 8.79 & 74.99 \\
\hline AD13 & 0.65 & 0.34 & 0.01 & 4846 & 5.60 & 8.73 & 75.60 \\
\hline AD14 & 0.69 & 0.30 & 0.01 & 5229 & 5.90 & 13.17 & 61.96 \\
\hline
\end{tabular}


Lucas Albert Jerome Hamidu, Umar Omeiza Aroke, Odeh Adey Osha, and Idris Misau Muhammad

Table 3: Determined Responses of Resin R7 Produced Adhesives

\begin{tabular}{|c|c|c|c|c|c|c|c|}
\hline Adhesive & R7 & PLZ & AOX & $\mu$ (cPc) & pH & $\% M C$ & $\%$ SC \\
\hline AD1 & 0.76 & 0.23 & 0.01 & 5267 & 5.50 & 17.46 & 67.01 \\
\hline AD2 & 0.79 & 0.20 & 0.01 & 3006 & 4.50 & 5.93 & 67.19 \\
\hline AD3 & 0.72 & 0.27 & 0.01 & 5285 & 4.10 & 15.18 & 58.36 \\
\hline AD4 & 0.65 & 0.34 & 0.01 & 5228 & 4.10 & 11.01 & 61.39 \\
\hline AD5 & 0.65 & 0.34 & 0.01 & 5230 & 4.10 & 11.03 & 61.41 \\
\hline AD6 & 0.79 & 0.20 & 0.01 & 3005 & 4.55 & 6.08 & 66.93 \\
\hline AD7 & 0.79 & 0.20 & 0.01 & 3005 & 4.50 & 5.73 & 66.82 \\
\hline AD8 & 0.79 & 0.20 & 0.01 & 3006 & 4.56 & 6.84 & 67.36 \\
\hline AD9 & 0.79 & 0.20 & 0.01 & 2999 & 4.51 & 5.71 & 67.12 \\
\hline AD10 & 0.76 & 0.23 & 0.01 & 5268 & 5.49 & 17.50 & 66.89 \\
\hline AD11 & 0.65 & 0.34 & 0.01 & 5227 & 4.11 & 11.02 & 61.42 \\
\hline AD12 & 0.65 & 0.34 & 0.01 & 5228 & 4.10 & 11.10 & 61.39 \\
\hline AD13 & 0.65 & 0.34 & 0.01 & 5228 & 4.10 & 11.05 & 61.40 \\
\hline AD14 & 0.69 & 0.30 & 0.01 & 5351 & 4.07 & 40.47 & 48.41 \\
\hline
\end{tabular}

\subsection{RESPONSE SURFACE OPTIMIZATION MODELING STATISTICAL AND DATA ANALYSES}

The mixture design matrix for the optimization modeling was based on the D-Optimal response specific for categorical factors generated by the software which minimize errors associated with the model coefficient throughout the modeling. In order to determine the fitness and significance of the models, ANOVA and sequential model sum of squares (SMSS) analysis was carried out (Tables of values for ANOVA and SMSS are not shown). The ANOVA shows the effects of individual responses and variables interaction on the D-optimal mixture and while SMSS evaluated individual responses to suggest the best model for the design. The F-value compares the variation of the differences in average responses at the design points and its corresponding responses using any of the models from replicated design point. The Prob $>\mathrm{F}$ values is the probability of actualizing the F-value which should be less than 0.0500 for significant model or greater than 0.0500 for insignificant model were used in selection of the model [19]. The SMSS shows the individual model analysis by various statistical data for adjusted and Predicted $\mathrm{R}^{2}$, standard deviations, precision accuracy and predicted error sum of squares (PRESS) values, which suggests the best fitting design by any of the following: linear, 2FI, quadratic, special cubic and cubic model for the fitness [32].

\subsection{VISCOSITY RESPONSE MODELING FOR R1AD, R4AD AND R7AD PRODUCED ADHESIVES}

The viscosity response ANOVA for R1AD, R4AD and R7AD adhesives was evaluated and analyzed using F-value and Prob>F values statistical tools. The ANOVA model F-values and Prob>F values for R1AD, R4AD and R7AD adhesives shows significant models for the produced adhesives, thus a model term is significant when the Prob $>F$ value is less than 0.0500 with high F-value leading to precision adequacy greater than 4 [16], [19]. Individual model for different coefficient for R1AD adhesive shows that linear mixture AB model are significant model while AC and $\mathrm{BC}$ are not significant models for Prob $>\mathrm{F}$ values were greater than 0.0500 . The R4AD adhesive ANOVA model shows that coefficients B and B2 are significant models for Prob $>F$ values are less than 0.0500 while coefficients $C, C 2$ and $\mathrm{BC}$ are not significant models as Prob $>\mathrm{F}$ values is greater than 0.0500 . Similarly, the R7AD adhesive ANOVA indicates model that coefficients B and B2 are significant models with Prob $>$ F values of less than 0.0500 and coefficients $C, C 2$ and $\mathrm{BC}$ are not significant models. The viscosity response was further evaluated by SMSS for individual adhesive produced and analyzed using the statistical data to suggest the best model that fits the design for validation and selection. The best model was fitted according to high F-value, low Prob $>F$ value, low standard deviations and high $\mathrm{R}^{2}$ values for both adjusted and predicted [32]. The quadratic model was found to be the best fit for R1AD produced adhesive with low standard deviation and Prob $>F$ less than 0.0500 for acceptable model. Two models (quadratic and cubic) was suggested for R4AD produced adhesive, however, cubic model having the least standard deviation, high $\mathrm{R}^{2}$ for both adjusted and predicted values adequately fitted the model. Similarly, R7AD produced adhesive is also fitted with cubic model having high adjusted and predicted $\mathrm{R}^{2}$ values with less than 0.2 differential for the 
determination of responses [16],[34] and low standard deviation [30]. Equations (4-6) are the generated polynomial model equations for viscosity responses (R1AD, R4AD and R7AD) respectively.

$$
\begin{aligned}
& \text { Viscosity R1AD }=-956.13879 * \mathrm{~A}+13449.55516 * \mathrm{~B}-956.13879 * \mathrm{C} \ldots(4) \\
& \begin{aligned}
\text { Viscosity R4AD } & =+1822.50676+19652.06392 * \mathrm{~B}+2.36315 \mathrm{E}+005 * \mathrm{C}-45291.17459 * \mathrm{~B} 2-1.61899 \mathrm{E}+007 * \mathrm{C} 2 \\
& +2.52580 \mathrm{E}+005 * \mathrm{~B} * \mathrm{C} \\
\text { Viscosity R7AD } & =-66065.55977+1.69363 \mathrm{E}+005 * \mathrm{~B}+9.85741 \mathrm{E}+006 * \mathrm{C} \\
& -5.11494 \mathrm{E}+008 * \mathrm{C} 2-5.49558 \mathrm{E}+005 * \mathrm{~B} * \mathrm{C} \quad \ldots(6)
\end{aligned}
\end{aligned}
$$

Where $\mathrm{A}=$ Resin $(\mathrm{R}), \mathrm{B}=$ Plasticizer (PLZ) and C = Antioxidant (AOX).

The diagnostic plots (not shown) for viscosity R1AD response showed a linear plot suggesting the trend of the modeled data. The viscosity R4AD response shows an over prediction of values which occur above with cluster points appearing, an indication that the model has problems resulting to high PRESS values and standard deviation from the actual values [16], [30]. The viscosity R7AD response shows that point below was over predicted resulting to deviation at 2999.00 (under predicted between 4373.23 and 5060.41 while over predicted between 5060.41 and 5747.55). These trends have resulted into high deviation of the actual values from the predicted values. However, the viscosity precision which is greater than 4 was adequate for the model acceptance [23].

\subsection{PH RESPONSE MODELING FOR R1AD, R4AD AND R7AD PRODUCED ADHESIVES}

The $\mathrm{pH}$ values for the ANOVA modeling were significant for all produced adhesives (R1AD, R4AD and R7AD), with high F-values and Prob>F values less than 0.0500 for the model coefficients. This implies that the $\mathrm{pH}$ of the produced adhesives was in conformity with the ANOVA modeling which has statistical values of Prob $>$ F values less than 0.0001 for the model [23], [30]. The pH response by SMSS for all produced adhesives showed agreement for the predicted and adjusted $\mathrm{R}^{2}$ values, which suggested the response was best modeled with cubic model. Various model analyses for $\mathrm{pH}$ response shows low standard deviation, PRESS and high precision accuracy in cubic model. The model produced adequate precision ratios signifying desirable signal greater than 4 [34]. Equations (7-9) are the suggested pseudo polynomial model equations used in terms of actual components to determine the model diagnostic case plots (not shown).

$$
\begin{aligned}
& \mathrm{pH} \text { R1AD }=+3.50-1973.01 * \mathrm{~B}+2.745 \mathrm{E}+005 * \mathrm{C}+5935.70 * \mathrm{~B} 2-1.162 \mathrm{E}+008 * \mathrm{C} 2 \quad+6039.53 * \mathrm{~B} * \mathrm{C} \\
& -3960.17 * \mathrm{~B} 3+1.092 \mathrm{E}+010 * \mathrm{C} 3 \quad-5.582 \mathrm{E}+005 * \mathrm{~B} 2 * \mathrm{C}+7.702 \mathrm{E}+007 \\
& * \mathrm{~B} * \mathrm{C} 2
\end{aligned}
$$

$$
\begin{aligned}
& \text { pH R4AD }=+5.42 * \mathrm{~A}+5.61 * \mathrm{~B}+1.900 \mathrm{E}+009 * \mathrm{C}-0.38 * \mathrm{~A} * \mathrm{~B}-2.860 \mathrm{E}+009 * \mathrm{~A} * \mathrm{C} \quad-2.853 \mathrm{E}+009 * \mathrm{~B} * \mathrm{C} \\
& +1.914 \mathrm{E}+009 * \mathrm{~A} * \mathrm{~B} * \mathrm{C}-353.04 * \mathrm{~A} * \mathrm{~B} *(\mathrm{~A}-\mathrm{B}) \quad+9.602 \mathrm{E}+008 * \mathrm{~A} * \mathrm{C} *(\mathrm{~A}-\mathrm{C})+9.534 \mathrm{E}+008 \\
& * \mathrm{~B} * \mathrm{C} *(\mathrm{~B}-\mathrm{C}) \\
& \mathrm{pH} 7 \mathrm{RD}=+4.52+1171.42 * \mathrm{~B}-1.636 \mathrm{E}+005 * \mathrm{C}-3516.43 * \mathrm{~B} 2+6.920 \mathrm{E}+007 * \mathrm{C} 2 \quad-3602.82 * \mathrm{~B} * \mathrm{C} \\
& +2344.60 * \mathrm{~B} 3-6.505 \mathrm{E}+009 * \mathrm{C} 3+3.314 \mathrm{E}+005 * \mathrm{~B} 2 * \mathrm{C} \quad-4.572 \mathrm{E}+007 * \mathrm{~B} \\
& * \mathrm{C} 2
\end{aligned}
$$

The $\mathrm{pH}$ of R1AD produced adhesive showed cluster points between 3.10 and 3.90 which implies under prediction, low $\mathrm{pH}$ value (acidic) which is not acceptable property of adhesive, thus highly acidic will accelerates rapid weakening of substrate which determines the procuring of adhesive in application [13], [28], furthermore, between 5.50 and 6.30 another cluster points occur implying over prediction [34]. The pH of R4AD produced adhesive shows no cluster points or any observed scattered points above and below the curve; this implies that the predicted values were adequately fitted resulting to low standard deviations from the actual experimental values. All $\mathrm{pH}$ values from this model are greater than 4 implying the adhesive is adequately fitted for all parameters [27]. Nevertheless, cubic model which exhibits high standard values with lowest standard deviation of 0.012 and high $\mathrm{R}^{2}$ values for both adjusted and predicted was most fitting for the model. The pH of R7AD produced adhesive shows agreement between the actual experimental and predicted values, the observed cluster points indicate there was no 
Lucas Albert Jerome Hamidu, Umar Omeiza Aroke, Odeh Adey Osha, and Idris Misau Muhammad

over prediction or under prediction. There was adequate correlation between the predicted and actual values which suggested cubic model as the best fitted with low standard deviation, high precision accuracy and less PRESS values among others.

\subsection{MOISTURE CONTENT RESPONSE MODELING FOR R1AD, R4AD AND R7AD PRODUCED ADHESIVES}

The ANOVA model "F-values and Prob>F values for R1AD, R4AD and R7AD adhesives indicate significant models, with exception of individual model coefficient AB for R1AD adhesive which has Prob $>F$ value 0.7729 greater than the standard value of 0.0500 [16]. However; other model coefficients for all produced adhesives were found significant for the moisture content response. Furthermore, it can be inferred from SMSS that R1AD, R4AD and R7AD produced adhesives statistical data satisfied cubic models indicating the significant effect of the independent variables on the responses. Equations (10-12) are the generated polynomial model equations for percentage moisture content.

$$
\begin{aligned}
& \% \text { MC R1AD }=+11.09+3015.33 * \mathrm{~B}-4.275 \mathrm{E}+005 * \mathrm{C}-9043.43 * \mathrm{~B} 2+1.809 \mathrm{E}+008 * \mathrm{C} 2 \quad-9164.03 * \mathrm{~B} * \mathrm{C} \\
& +6028.59 * \mathrm{~B} 3-1.700 \mathrm{E}+010 * \mathrm{C} 3 \quad+8.697 \mathrm{E}+005 * \mathrm{~B} 2 * \mathrm{C}-1.201 \mathrm{E}+008 \\
& * \mathrm{~B} * \mathrm{C} 2
\end{aligned}
$$
\%MC R4AD $=+10.84+5120.08 * \mathrm{~B}-7.132 \mathrm{E}+005 * \mathrm{C}-15352.94 * \mathrm{~B} 2+3.017 \mathrm{E}+008 * \mathrm{C} 2-15124.35 * \mathrm{~B} * \mathrm{C}$ $+10230.83 * \mathrm{~B} 3-2.836 \mathrm{E}+010 * \mathrm{C} 3 \quad+1.450 \mathrm{E}+006 * \mathrm{~B} 2 * \mathrm{C}-2.002 \mathrm{E}+008$
\%MC R7AD $=+6.00+30710.43 * \mathrm{~B}-4.293 \mathrm{E}+006 * \mathrm{C}-92062.52 * \mathrm{~B} 2+1.816 \mathrm{E}+009 * \mathrm{C} 2-91615.60 * \mathrm{~B} * \mathrm{C}$ $+61357.11 * \mathrm{~B} 3-1.707 \mathrm{E}+011 * \mathrm{C} 3 \quad+8.723 \mathrm{E}+006 * \mathrm{~B} 2 * \mathrm{C}-1.204 \mathrm{E}+009$
$* \mathrm{~B} * \mathrm{C} 2$

The corresponding diagnostic case plots (not shown) shows significant adequate relationship between the predicted models and actual experimental values for \%MC R7AD response while R1AD and R4AD has cluster points at the middle implying slight deviation between the predicted and actual values.

\subsection{SOLID CONTENT RESPONSE MODELING FOR R1AD, R4AD AND R7AD PRODUCED ADHESIVES}

The percentage solid content response for R1AD shows that the cubic model was statistically significant (Prob<0.0027), although 2FI model was significant (Prob<0.0413) which indicates that the model adequately describes R1AD adhesives; nevertheless, the model with lower Prob>F values best describe the model. For the R4AD adhesive, both the linear (Prob $<0.026)$ and cubic model (Prob $<0.0001)$ were statistically significant and both predicted and actual $\mathrm{R}^{2}$ values was higher in cubic than the linear, $2 \mathrm{FI}$ and quadratic models. The standard deviations (0.21) in cubic model adequately describe the significance for consideration as the best fit. Furthermore, the cubic model was statistically significant (Prob $<0.0001$ ) for R7AD, which indicates that the model adequately describes the response. Equations (13-15) are the cubic polynomial generated models for percentage solid content responses diagnostic cases using model coefficient for R1AD, R4AD and R7AD adhesives respectively.

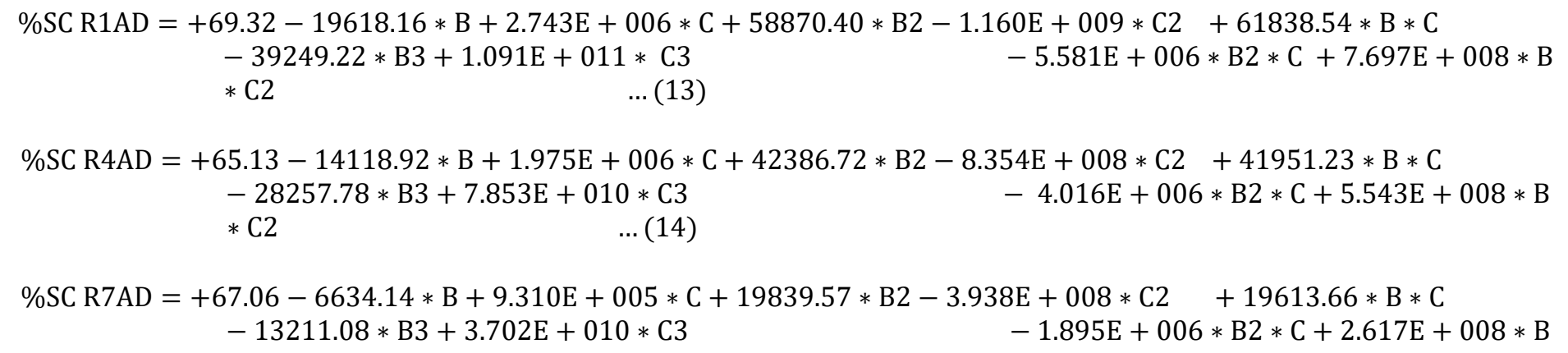


The corresponding diagnostic cases plots (not shown) from the model coefficients for predicted and actual experimental values for R1AD shows scattered points above and below the diagonal line; when scattered plots occur in a model, it shows over prediction or under prediction of values and deviations [34]. For both R4AD and R7AD the points were linear along the diagonal signifying agreement between the predicted and actual experimental values, thus the predicted model obtained using D-Optimal for mixture was significantly adequate for R4AD and R7AD produced adhesives.

\subsection{MODEL OPTIMIZATION SOLUTION AND VALIDATION}

The prediction of optimum from responses of the produced adhesives were evaluated using design expert optimization parameters based on the constraints conditions for the standard requirement of quality adhesives for particleboard production. Several optimization models were suggested for the analyses to determine the best adhesive and its validation for navigation. Table 4 presents the model solutions for each resin produced adhesives (R1AD, R4AD and R7AD) with the desirability values and the best model selected.

Table 4: Validation of Optimization Modeling Solutions of R1AD, R4AD and R7AD Produced Adhesives

\begin{tabular}{|c|c|c|c|c|c|c|c|c|c|}
\hline Adhesive & R1 & PLZ & $\mathrm{AOX}$ & Viscosity & $\mathrm{pH}$ & $\% \mathrm{MC}$ & $\%$ SC & Desirability & \\
\hline AD1 & 0.76 & 0.23 & 0.01 & 2398.46 & 5.146 & 4.129 & 68.196 & 0.664 & Selected \\
\hline $\mathrm{AD} 2$ & 0.75 & 0.24 & 0.01 & 2450.39 & 5.474 & 4.742 & 67.840 & 0.659 & \\
\hline AD3 & 0.75 & 0.24 & 0.01 & 2439.15 & 5.343 & 4.246 & 68.213 & 0.649 & \\
\hline Adhesive & $\mathrm{R} 4$ & PLZ & AOX & Viscosity & $\mathrm{pH}$ & $\% \mathrm{MC}$ & $\%$ SC & Desirability & \\
\hline $\mathrm{AD} 1$ & 0.68 & 0.31 & 0.01 & 5151.70 & 6.192 & 10.000 & 70.447 & 0.737 & Selected \\
\hline AD2 & 0.72 & 0.27 & 0.01 & 5223.58 & 5.523 & 10.001 & 74.262 & 0.675 & \\
\hline AD3 & 0.79 & 0.20 & 0.01 & 5199.57 & 5.534 & 9.079 & 70.000 & 0.648 & \\
\hline $\mathrm{AD} 4$ & 0.78 & 0.21 & 0.01 & 5172.87 & 5.207 & 9.964 & 70.000 & 0.634 & \\
\hline Adhesive & R7 & PLZ & AOX & Viscosity & $\mathrm{pH}$ & $\% \mathrm{MC}$ & $\% \mathrm{SC}$ & Desirability & \\
\hline AD1 & 0.68 & 0.31 & 0.01 & 3625.88 & -0.441 & -22.999 & 60.000 & 0.858 & \\
\hline AD2 & 0.79 & 0.20 & 0.01 & 2942.49 & 4.308 & 3.989 & 67.6325 & 0.736 & Selected \\
\hline AD3 & 0.74 & 0.25 & 0.01 & 5162.22 & 4.000 & 1.732 & 64.5242 & 0.691 & \\
\hline
\end{tabular}

Three (3) solutions were found for R1AD adhesive formulations from the optimization modeling numerical solutions with AD1 composition R1, PLZ and AOX equal to $0.76,0.23$ and 0.01 respectively with desirability factor of 0.664 was the best fitted formulation selected, furthermore, four (4) solutions were found for R4AD adhesive formulations with AD1 composition R4, PLZ and AOX equal to $0.68,0.31$ and 0.01 respectively with desirability factor 0.737 was the best formulation selected and finally, three (3) solutions were found for R7AD adhesive formulations with AD2 composition R7, PLZ and AOX equal to $0.79,0.20$ and 0.01 respectively with desirability factor 0.736 was the best formulation selected but not AD1 with 0.858 desirability factor due to negativity value of $\mathrm{pH}$ and $\mathrm{MC}$ which is undefined in modeling. Based on validation of optimization modeling solutions (Table 4), the general selection of adhesive based on desirability factor and in line with experimental analyses from the responses:

R7AD2>R1AD1>R4AD1.

\section{CONCLUSION}

In this work, practical approaches based on the statistical analyses were used to develop the best formulation matrix and model for polystyrene waste adhesive production. Resins were formulated based on 2 factorial mixture DOE, followed by 3 factorial mixture DOE for adhesive formulation with 4 responses namely: viscosity, pH, percentage moisture content and percentage solid content using D-optimal mixture design for their analyses. The ANOVA models for produced adhesives (R1AD, R4AD and R7AD) all showed significant models as commonly used to describe other processes, however, the optimization formulation was predicted based on the polynomial model equations generated by design expert software and the use of statistically define model parameters for the selection of the best fitted model and its predictions which identified the best produced adhesive in descending order as: R7AD2>R1AD1>R4AD1. The use of D-optimal in analyzing the responses has also demonstrated the minimization of 
Lucas Albert Jerome Hamidu, Umar Omeiza Aroke, Odeh Adey Osha, and Idris Misau Muhammad

errors and suggesting the alternative design to the model having aliases which might result into errors in the modeling.

\section{SOURCES OF FUNDING}

This research received no specific grant from any funding agency in the public, commercial, or not-for-profit sectors.

\section{CONFLICT OF INTEREST}

The author have declared that no competing interests exist.

\section{ACKNOWLEDGMENT}

The authors gratefully acknowledge the use of water and civil laboratory of Abubakar Tafawa Balewa University Bauchi and Nigerian Building and Road Research Institute, North Central Zonal Office Jos-Plateau State, Nigeria for using their facilities.

\section{REFERENCES}

[1] Abdulkareem, S. A., Raji, A. S and Adeniyi, A. G (2017). Development of Particleboard from Waste Styrofoam and Sawdust. Nigerian Journal of Technological Development, 14(1), 18 - $22 . \quad$ Doi: http://dx.doi.org/10.4314/njtd.v14i1.3.

[2] Abdulkarim, I.I., Kundiri, A.M. and Abbagana, M. (2019). Predicting CBR Values of Black Cotton Soil Stabilized with Cement and Waste Glass Admixture Using Regression Model. American Journal of Traffic and Transportation Engineering, 4(1), 31. doi: 10.11648/j.ajtte.20190401.15.

[3] Ademović, Z., Suljagić, J., Zulić, J. (2017). Influence of Physical Properties on Thermal Conductivity of Polystyrene Insulation Materials Contemporary Materials, 8(1), 42 - 47. Doi: 10.7251/COMEN1701042A.

[4] Akinterinwa, A., Osemeahon, S. A., Nkafamiya, I. I. and Dass, P. M. (2015). Formulation of Emulsion Paint from a Copolymer Composite of Dimethylol Urea/Polystyrene; Journal of Chemistry and Materials Research. 7(7), 20 - 26.www.iiste.org.

[5] Arendt, W. D., McBride, E. and Conner, M. M. (2014a). Use of Dibenzoate Plasticizers in Pressure-Sensitive Adhesives, Applications Chemist Emerald Kalama Chemical LL. C Kalama Washington.

[6] Arendt, W. D., McBride, E. and Hanes, R. D. (2014b). New Dibenzoate Plasticizer Blends for PVC Applications; Journal of Vinyl and Additive Technology, 20(3), 137 - 142. Doi:10.1002/vnl.21343.

[7] Arsenovic, M., Pezo, L. and Radojevic, Z. (2012). Response surface method as a tool for heavy clay firing process optimization: Roofing tiles. Processing and Application of Ceramics, 6(4), 209-214. doi: 10.2298/pac1204209a.

[8] Barry, C. P., Morose, G. J., Begin, K., Atwater, M. and Hansen, C. J. (2017). The Identification and Screening of Lower Toxicity Solvents for Contact Adhesives. International Journal of Adhesion and Adhesives. 78(2017), 174 - 181. http. // dx. doi.org/10.1016/J.Jadhadh.2017.06.022.

[9] Bastani, A., Militz, H., Adamopoulos, S. and Rohumaa, A. (2016). Development of Bonding Strength of Modified Birch Veneers during Adhesive Curing, Journal of Wood Research. 61(2), 205 - 214.

[10] Chanhoun, M., Padonou, S., Adjovi, E. C., Olodo, E. and Doko, V. (2018). Study of the Implementation of waste wood, Plastics and Polystyrene for various Applications in Building Industry; Journal of Construction and Building Materials. 167(1), 936 - 941.https://doi.org/10.1016/j.conbuildmat.2018.02.080.

[11] Chauhan, B. and Gupta, R. (2004). Application of statistical experimental design for optimization of alkaline protease production from Bacillus sp. RGR-14. Process Biochemistry, 39(12), 2115-2122. doi: 10.1016/j.procbio.2003.11.002.

[12] Derikvand, M. and Pangh, H. (2016). A Modified Method for Shear Strength Measurement of Adhesive Bonds in Solid Wood, Peer-Review Article; Adhesive Bond Strength, BioResources. 11(1), 354 - 364. 
[13] Elbadawi, M., Osman, Z., Paridah, T., Nasroun, T. and Kantiner, W. (2015). Mechanical and Physical Properties of Particleboards made from Ailanthus Wood and UF resin Fortified by Acacias Tannins Blend. Journal of Materials and Environmental Sciences. 6(4), 1016 - 1021.

[14] El-Malah, Y., Nazzal, S. and Khanfar, N. M. (2006). D-Optimal Mixture Design: Optimization of Ternary Matrix Blends for Controlled Zero-Order Drug Release From Oral Dosage Forms, Drug Development and Industrial Pharmacy, 32:1207-1218, DOI: 10.1080/03639040600685167.

[15] Facts About Landfill and Styrofoam (2018). https://Sciencing.com.

[16] Gryze, Langhans and Vandebroek. (2007). Using the correct Intervals for Prediction Actual on Tolerance Intervals of Ordinary Least-squares Regression. Chemometrics and Intelligent Laboratory System. 87(2), 147 $-154$.

[17] Hamidu, L. A. J., Aroke U. O., Osha, O. A. and Muhammad, I. M. (2019). Formulation and Characterization of Adhesive Produced from Polystyrene Waste Using Response Surface Optimization; Path of Science. 2019. 5(8), 2000 - 2009. DOI: 10.22178/pos.49-2; ISSN 2413-9009.

[18] Haslego, C. (2010). Basics of Polystyrene Production, Chemical and Process Engineering Resources, 2010.

[19] Jeirani, Z., Jan, B. M., Ali, B. S., Noor, I. M., Hwa, S. C. and Saphanuchart, W. (2012). The Optimal Mixture Design of Experiments: Alternative Method in Optimizing the Aqueous Phase Composition of a Microemulsion, Chemometrics and Intelligent Laboratory Systems. 112 (2012) 1-7; DOI: 10.1016/j.chemolab.2011.10.008.

[20] Koocheki, A., Taherian, A., Razavi, S., and Bostan, A. (2009). Response surface methodology for optimization of extraction yield, viscosity, and hue and emulsion stability of mucilage extracted from Lepidium Perfoliatum Seeds. Food Hydrocolloids, 23, 2369-2379.

[21] Li, R., Guo, X., Ekevad, M., Marklund, B. and Cao, P. (2015). "Investigation of Glue line Shear Strength of Pine Wood Bonded with PVAc by Response Surface Methodology," Journal of BioResources. 10(3), 3831 - 3838.

[22] Mancenido, M. V., Pan, R., Montgomery, D.C., Anderson-Cook, C. M. (2019). Comparing D-optimal designs with common mixture experimental designs for logistic regression, Chemometrics and Intelligent Laboratory Systems 187 (2019) 11-18, https://doi.org/10.1016/j.chemolab.2019.02.003.

[23] Miller, D. (1984). Reducing Transmission Bias in Curve Fitting. The American Statistician. 38(2), 124 - 126.

[24] Now and Forever: The Styrofoam Dilemna. (2016). Retrieved from Canada.com: http://www.canada.com/life/forever Styrofoam dilemma/1522634/story.html.

[25] Olubajo, O. O. and Makarfi, I. Y. (2019). Prediction and Optimization of Sulphur Trioxide Yield from Calcination of Aluminium Sulfate Using Central Composite Design, Path of Science. 5(10), 1001 - 1013. doi:10.22178/pos.51 - 2 .

[26] O’Brien, E. P., Germinario, L. T., Robe, G. R., Williams, T., Atkins, D. G., Moroney, D. A., Mark A. and Peters, M. A. (2007). Fundamentals of Hot-Melt Pressure-Sensitive Adhesive Tapes: The Effect of Tackifier Aromaticity, Journal of Adhesion Science Technology, 21(7), 637 - 661.

[27] Pan, Z., Zheng, Y., Zhang, R. and Jenkins B. M. (2007). Physical Properties of Thin Particleboard from Saline Eucalyptus, Industrial Crop Products, 26(2007), 185 - 194.doi: 10.1016/j.indcrop.2007.03.006.

[28] Pan, Z., Cathcart, A. and Wang, D (2005). Thermal and chemical treatments to improve adhesive property of rice bran, Industrial Crops and Products, An International Journal, 22(2005), 233 - 240.doi: 10.1016/j.indcrop.2005.01.003.

[29] Polystyrene Fact Sheet (November, 2017). www.cleanup.org.au Retrieved 03/07/2019.

[30] Richard Buxton (2007). Mathematical Learning Support Center, Design Expert 7 Tutorial, 1 -10.

[31] Roffel, B. and Betlem, B. (2006). Process Dynamics and Control Modeling for Control and Prediction, Copyright (C) 2006 John Wiley \& Sons Ltd The Atrium, Southern Gate, Chichester, West Sussex P019 8SQ, England Telephone (+44) 1243779777.

[32] Sarteshnizi, R. A., Hosseini, H., Bondarianzadeh, D., Colmenero, F. J., Khaksar, R. (2015). Optimization of prebiotic sausage formulation: Effect of using b-glucan and resistant starch by D-optimal mixture design approach, LWT - Food Science and Technology $62 \quad$ (2015) $704 \quad-\quad 710$. http://dx.doi.org/10.1016/j.lwt.2014.05.014.

[33] Sekharan, R. V., Abraham, B. T. and Thachil, E. T. (2012). Utilization of waste expanded polystyrene: Blends with silica-filled natural rubber, Journal of Materials and Design 40(1) 221-228. Doi:http://dx.doi.org/10.1016/j.matdes.2012.03042.

[34] Shari, K. (2018). How to get started with design expert software. Pages 1 - 53, retrieved on 6/1/2018 at http://www.statease.com/pubs/doe-keys.pdf. 
[35] Silva, F. B. M., Vianna, R. F. and Neubert, E. I. (2014). Study of Adhesion Properties of Natural Rubber - Based Pressure Sensitive Adhesive with Variation of Tackifier Resin and Plasticizers Agents, Area tematica: Engenharia de Materials e Nanotecnologia; 1(2014), 1 - 8.

[36] Stewart, D. C. (No Date). Antioxidant Optimization in Pressure Sensitive Adhesives Using Modulated Thermogravimetric Analysis. Analytical Chemist, Intertape Polymer Group, Marysville, MI. Pages 113 - 123. Retrieved 11 August, 2018.

[37] Strickland, Barbara (2013). Introduction to Adhesives UPACO Division of Worthen Industries, April, 2013.

[38] Vodnik, V.V., Dzunuzovic, E.S. and Dzunuzovic, J.V. (2014). SYNTHESIS AND CHARACTERIZATION OF POLYSTYRENE BASED NANOCOMPOSITES In: Polystyrene: Synthesis, Characteristics and Applications, Editor: Cole Lynwood, Nova Science Publishers, Inc.

[39] Xenidou, M (2005). ASC Hot Melt Short Course, Senior Associate Henkel (formerly National Starch and Chemical Company), 10 Finerne Avenue Bridgewater, NJ, October 9, 2005.

[40] Zaibunnisa, A. H., Norashikin, S., Mamot, S. and Osman, H. (2009). An experimental design approach for the extraction of volatile compounds from turmeric leaves (Curcuma domestica) using pressurised liquid extraction (PLE). LWT - Food Science and Technology, 42(1), 233-238. Doi: 10.1016/j.lwt.2008.03.015.

[41] Zen, N. I. M., Gani, S. S. A., Shamsudin, R. and Masoumi, H. R. F. (2015). The Use of D-Optimal Mixture Design in Optimizing Development of Okara Tablet Formulation as a Dietary Supplement, The Scientific World Journal, http://dx.doi.org/10.1155/2015/684319 